\title{
UNESCO Chair of Biophysics and Molecular Neurobiology
}

\author{
Francisco J. Barrantes*
}

Instituto de Investigaciones Bioquímicas de Bahía Blanca, Argentina

The existence of a critical mass of talented scientists in the fields of Biophysics and Neurobiology in Latin America gave impetus to efforts to foster cooperation at the regional level.

Following on from a meeting of scientists from five South American countries in Caracas in 1989, a survey was carried out to determine which laboratories in the region were conducting leading-edge research in the area of Biophysics and Molecular Neurobiology, and to lay the basis for a coordinated network of human resources in these fields of research. The leadership of a few laboratories in Latin America emerged and a pipeline project was submitted to governmental bodies in Argentina, Brazil, Chile, Mexico, and Venezuela. At this stage no further progress was achieved owing to the lack of financial commitment at government level.

The project was then pursued in the form of a request to UNESCO in Paris for the creation of a Chair in the fields of Biophysics and Molecular Neurobiology. The candidacy of the Instituto de Investigaciones Bioquímicas de Bahía Blanca (INIBIBB) for this Chair was strongly supported by the Universidad Católica de Valparaíso, Chile, the Department of Physiology and Biophysics, Faculty of Medicine, Universidad de Chile, and the Department of Biochemistry, Federal University of Rio de Janeiro, Brazil. A key aspect of the request was the commitment of the designated Chair to capitalize on the existence of the first-rate laboratories in the region, making more efficient use of their teaching resources for the benefit of further education in these fields throughout Latin America. This proposal was aimed at providing a competitive alternative to the classical format of postgraduate students leaving for extended training in the Northern hemisphere, a scheme which more often than not results in the permanent emigration of the students. Offering South American students, particularly those from scientifically less well-endowed countries, the opportunity to benefit from high quality training of international standard in laboratories in the region emerged as a viable option to retain talent.

After four years of negotiations between UNESCO and the Universidad Nacional del Sur in Bahía Blanca, Argentina, the UNESCO Chair of Biophysics and Molecular Neurobiology was formally created in 1998.

The Chair is the first UNESCO programme in Argentina in the field of Biophysics and Molecular Neurobiology and

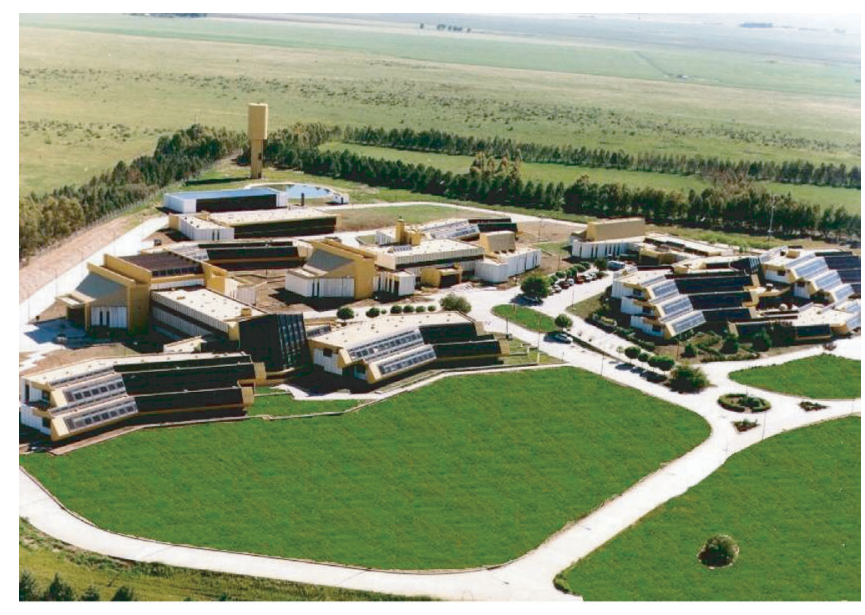

FIgure 1: Aerial view of the Institute for Biochemical Research / UNESCO Chair in Bahia Blanca, Argentina.

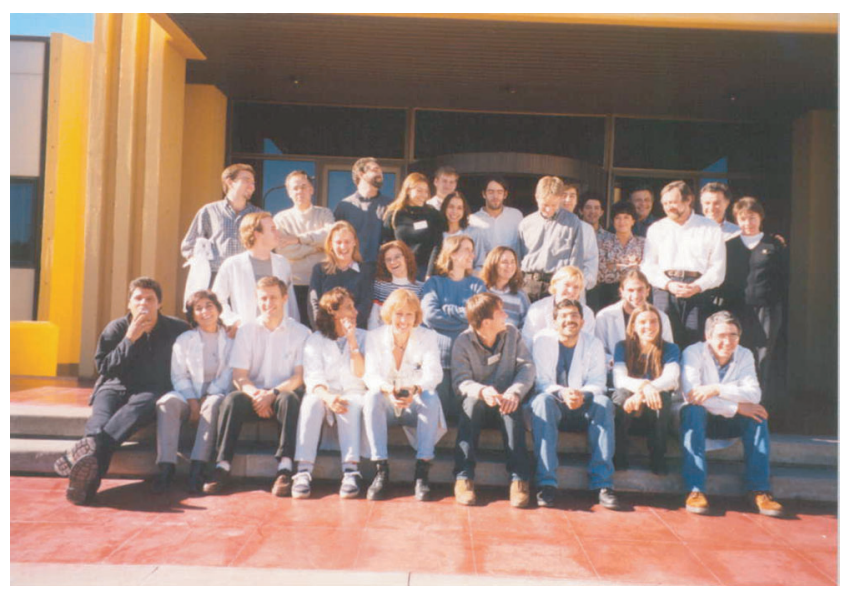

Figure 2: Students and faculty from Mexico, Uruguay, South Africa, Peru, Argentina, Chile, Portugal, Cuba, and Germany attending the UNESCO ICRO-IBRO-TWAS Postgraduate Course on "Spectroscopic and Physiological Approaches to Neurobiology" May-June, 2000.

builds on the initial efforts to foster cooperation in this area, aimed at maximizing the regional pool of expertise through 
the exchange of specialists of international standing and the training of students from all Latin America, thus laying the basis for a regular flow of South-South cooperation such that other developing countries might benefit.

Since its inception, academic activities have been exclusively centered on postgraduate teaching on a regular, yearly basis. Within this scheme, three international courses have been organized so far by F. J. Barrantes:

(1) “Topics in Biophysics of Membranes," April-November, 1999;

(2) "Novel Spectroscopic and Physiological Approaches to Neurobiology" (UNESCO ICRO-IBRO-TWAS Postgraduate Course), May 22-31, 2000; and

(3) "Spectroscopic and Physiological Advances in Neurobiology," April-August, 2001.

Students from different parts of the world (Mexico, Uruguay, South Africa, Peru, Argentina) have attended the courses, which have included the participation of visiting lecturers from renowned research centers throughout the world.

The teaching activities aim at highlighting the recent advances in Biophysics, particularly in the field of Neurobiology, accomplished through the novel application of bio- physical techniques. They also stress the importance of recent advances in our understanding of neurobiological problems, with an integrated molecule-to-cell view, emphasizing the need for interdisciplinary approaches towards this goal.

So far, the UNESCO Chair has had no regular budget and no permanent staff except for the ad honorem position of the professor-in-charge. Implementation of the activities undertaken to date, therefore, has relied on the ad hoc provision of funds from the Third World Academy of Sciences (TWAS), the International Brain Research Organization (IBRO); the International Cell Research Organization (ICRO), the Academia de Ciencias de América Latina (ACAL), and as from this year, the Universidad Nacional del Sur. These funds have been used to defray the cost of student travel and accommodation and to contribute towards the stay of some of the visiting professors, mostly from abroad. A continuum of collaboration and scientific contribution on the part of a number of prestigious academics at the international level has been secured by the organizer.

* Prof. Francisco J. Barrantes is in charge of UNESCO Chair of Biophysics and Molecular Neurobiology E-mail: rtfjb1@criba.edu.ar Fax: (054) 291 4861200; Tel: (054) 2914861201 

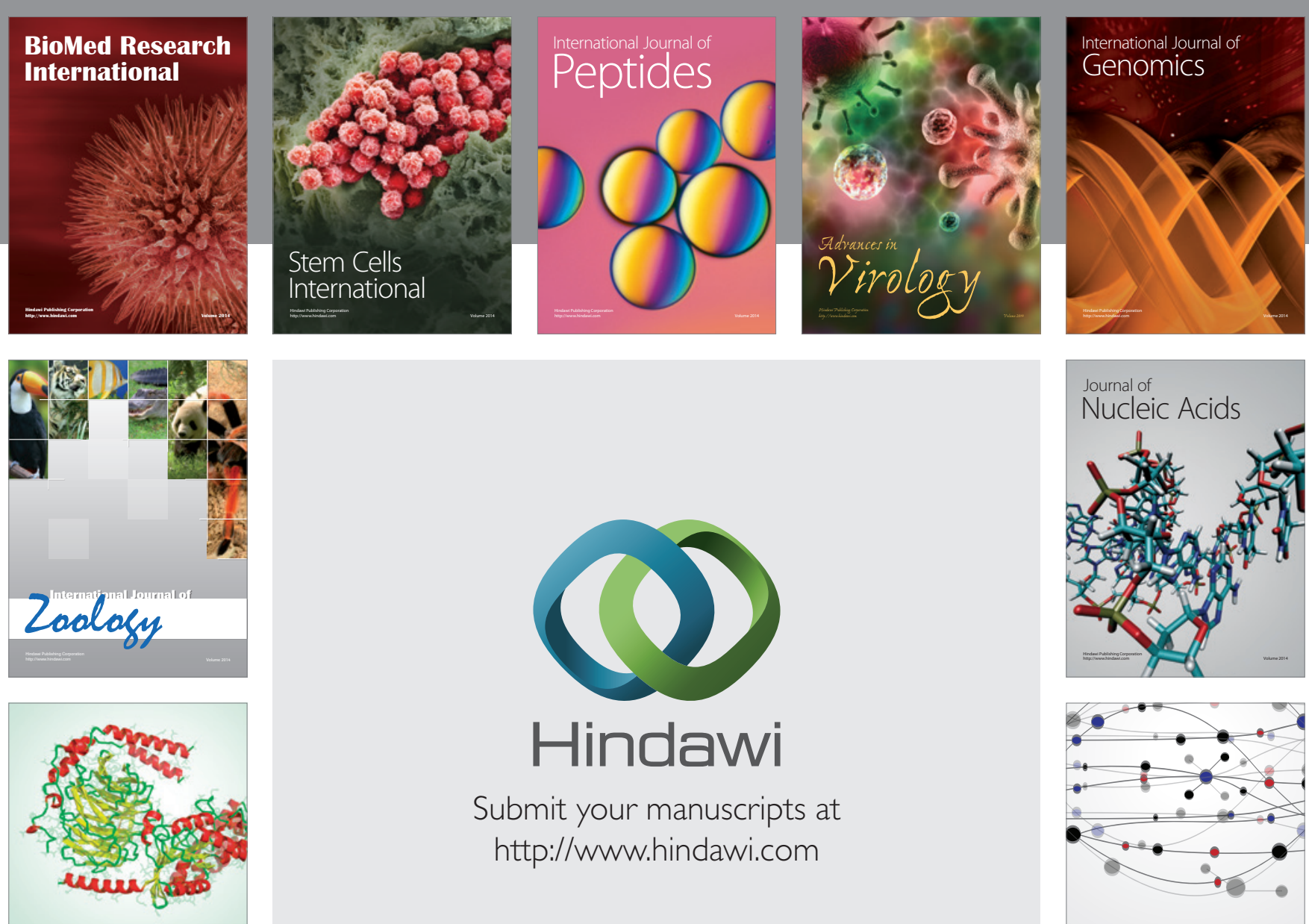

Submit your manuscripts at

http://www.hindawi.com

Signal ${ }^{\text {Jumal }}$ Transduction
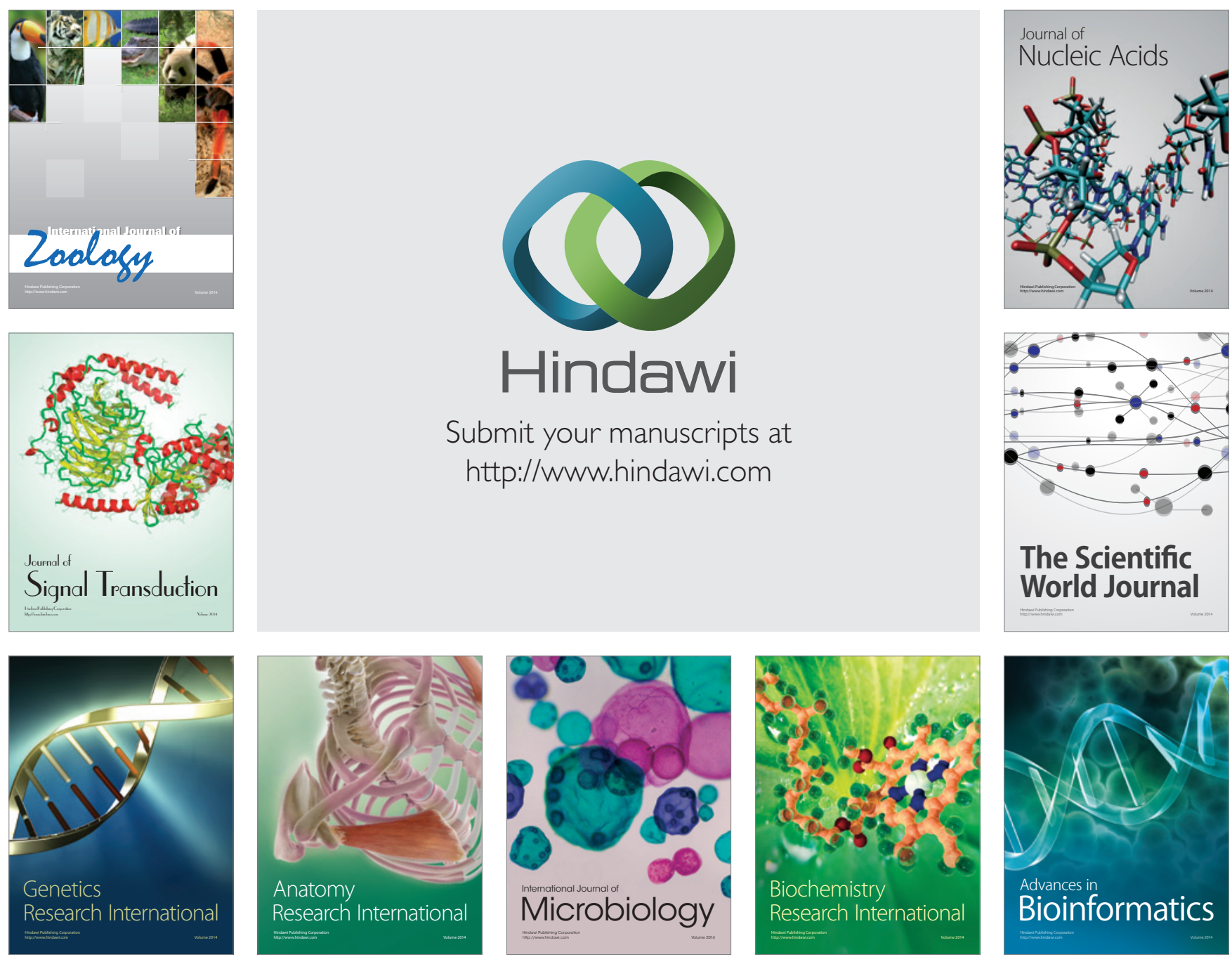

The Scientific World Journal
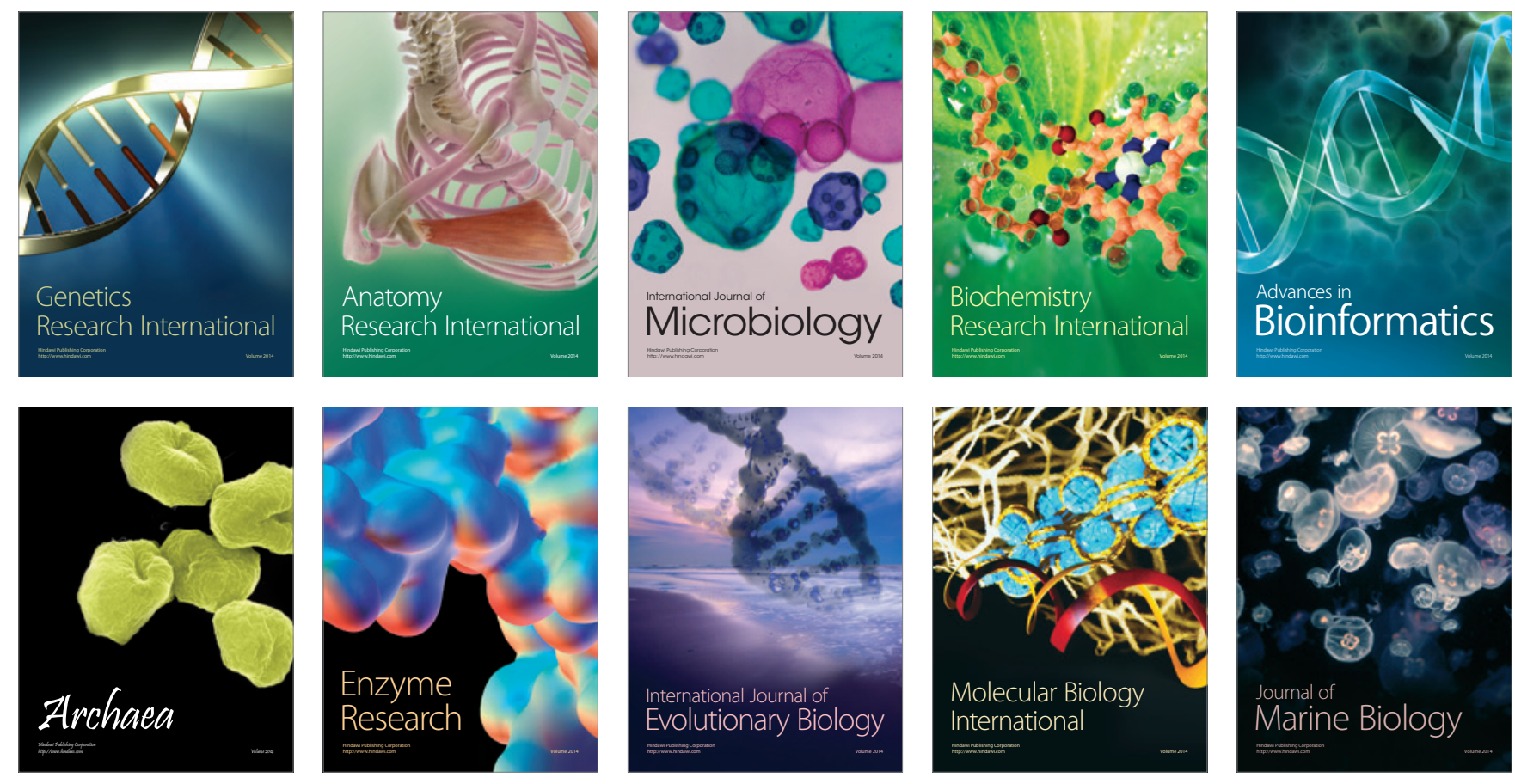